\title{
GENERALIZED HYERS-ULAM STABILITY OF MAPPINGS ON NORMED LIE TRIPLE SYSTEMS
}

\author{
Mohammad Sal Moslehian and Themistocles M. Rassias
}

Abstract. We prove the generalized Hyers-Ulam stability of mappings on normed spaces for the Pexiderized Cauchy-Jensen additive mapping

$$
f\left(\frac{x+y}{2}+z\right)+g\left(\frac{x-y}{2}-z\right)=h(x) .
$$

Then we apply the results for investigating the stability of homomorphisms and derivations on normed Lie triple systems.

Mathematics subject classification (2000): 39B82, 16W25, 17A40, 39B52, 47Jxx.

Key words and phrases: Pexiderized Cauchy-Jensen additive mapping; normed Lie system; homomorphism; derivation; generalized Hyers-Ulam stability.

\section{REFERENCES}

[1] M. Amyari AND M. S. Moslehian, Approxiamtely ternary semigroup homomorphisms, Lett. Math. Phys. 77 (2006), 1-9.

[2] T. AOKI, On the stability of the linear transformation in Banach spaces, J. Math. Soc. Japan 2(1950) 64-66.

[3] C. BaAK and M. S. Moslehian, Stability of $J^{*}$-homomorphisms, Nonlinear Anal.-TMA 63 (2005), 42-48.

[4] C. BaAK and M. S. Moslehian, On the stability of $\theta$-derivations on $J B^{*}$-triples, Bull. Braz. Math. Soc. 38 (2007), no. 1, 115-127.

[5] D. BURDE, Lie algebra prederivations and strongly nilpotent Lie algebras, Comm. Algebra 30 (2002), no. 7, 3157-3175.

[6] J. CHMIELIŃSKI AND S.-M. JUNG, On the stability of the Wigner equation on a restricted domain, J. Math. Anal. Appl. 254 (2001) 309à-320.

[7] S. CzERWIK, Functional Equations and Inequalities in Several Variables, World Scientific, New Jersey, London, Singapore, Hong Kong, 2002.

[8] V. FAĬZIEV, TH. M. RASSIAS AND P. K. SAHOO, The space of $(\psi, \gamma)$-additive mappings on semigroups Trans. Amer. Math. Soc. 354 (2002), no. 11, 4455-4472.

[9] Z. GAJDA, On stability of additive mappings, Internat. J. Math. Math. Sci. 14 (1991), 431-434.

[10] P. GĂVRUTA, A generalization of the Hyers-Ulam-Rassias stability of approximately additive mappings, J. Math. Anal. Appl. 184 (1994), 431-436.

[11] S. Helgason, Differential Geometry, Lie Groups and Symmetric Spaces, Academic Press, 1978.

[12] N. C. HOPKINS, Nilpotent ideals in Lie and anti-Lie triple systems, J. Algebra 178 (1995), 480à-492.

[13] D. H. HYERS, On the stability of the linear functional equation, Proc. Nat. Acad. Sci. U.S.A. 27 (1941), 222-224.

[14] D. H. Hyers, G. IsAC AND TH. M. Rassias, Stability of Functional Equations in Several Variables, Birkhäuser, Basel, 1998.

[15] D. H. Hyers AND TH. M. Rassias, Approximate homomorphisms, Aequationes Math. 44 (1992), $125-153$. 
[16] G. IsAC AND TH. M. RaSSIAS, Stability of $\psi$-additive mappings: Applications to nonlinear analysis, Internat. J. Math. Math. Sci. 19 (1996), 219-228.

[17] S.-M. JUNG, Hyers-Ulam-Rassias Stability of Functional Equations in Mathematical Analysis, Hadronic Press lnc. Palm Harbor, Florida, 2001.

[18] Y.-H. LEE AND K.-W. JUN, A generalization of the Hyers-Ulam-Rassias stability of Jensen's equation, J. Math. Anal. Appl. 238 (1999), 305-315.

[19] W. G. LISTER, A structure theory of Lie triple systems, Trans. Amer. Math. Soc. 72 (1952), 217-242.

[20] M. S. MosLEHIAN, Approximately vanishing of topological cohomology groups, J. Math. Anal. Appl. 318 (2006), 758-771.

[21] M. S. Moslehian AND TH. M. Rassias, Orthogonal stability of additive type equations, Aequationes Math., 73 (2007) 249-259.

[22] M. S. Moslehian AND TH. M. Rassias, Stability of functional equations in non-Arhimedian spaces, Appl. Anal. Disc. Math. 1 (2007), 325-334.

[23] S. OKUBO, Introduction to Octonion and Other Non-Associative Algebras in Physics, Montroll Memorial Lecture Series in Mathematical Physics, 2. Cambridge University Press, Cambridge, 1995.

[24] C. PARK, Lie *-homomorphisms between Lie $C^{*}$-algebras and Lie *-derivations on Lie $C^{*}$-algebras, J. Math. Anal. Appl. 293 (2004), 419-434.

[25] C. PARK, Homomorphisms between Lie JC* -algebras and Cauchy-Rassias stability of Lie JC ${ }^{*}$-algebra derivations, J. Lie Theory 15 (2005), 393-414.

[26] C. PARK, Isomorphisms between $C^{*}$-ternary algebras, J. Math. anal. Appl. (to appear).

[27] W.-G. PARK AND J.-H. BAE, On a CauchyàJensen functional equation and its stability, J. Math. Anal. Appl. (to appear).

[28] J. M. RASSIAS, On approximation of approximately linear mappings by linear mappings, J. Funct. Anal. 46 (1982), 126-130.

[29] TH. M. RASSIAS, On the stability of the linear mapping in Banach spaces, Proc. Amer. Math. Soc. 72 (1978), 297-300.

[30] TH. M. Rassias, Problem 16; 2, Report of the 27th International Symp.on Functional Equations, Aequationes Math. 39 (1990), 292-293; 309.

[31] TH. M. Rassias, On the stability of functional equations in Banach spaces, J. Math. Anal. Appl. 251 (2000), 264-284.

[32] TH. M. RASSIAS (ED.), Functional Equations, Inequalities and Applications, Kluwer Academic Publishers, Dordrecht, Boston and London, 2003.

[33] TH. M. RASSIAS AND P. SEMRL, On the behaviour of mappings which do not satisfy Hyers-Ulam stability, Proc. Amer. Math. Soc. 114 (1992), 989-993.

[34] S. M. Ulam, Problems in Modern Mathematics, Chapter VI, Science Editions, Wiley, New York, 1964. 